\section{AS VIVÊNCIAS DE UM GRUPO DE PACIENTES COM TRANSTORNOS ALIMENTARES: A RELAÇÃO COM O ESPELHO E A IMAGEM CORPORAL}

\author{
The Experiences of a Group of Patients with Eating Disorders: \\ The Relationship with the Mirror and Body Image
}

\author{
Experiencias de un Grupo de Pacientes con Trastornos de la \\ Conducta Alimentaria: La Relación con el Espejo y su Imagen \\ Corporal
}

\begin{abstract}
Les Expériences d'un Groupe de Patients Atteints de Troubles D'alimentation: La Relation avec le Miroir et L'image Corporelle
\end{abstract}

\begin{abstract}
Resumo
A incidência de transtorno alimentar (TA) na população vem aumentando progressivamente. Dentre os diferentes problemas relacionados à alimentação, destacam-se a anorexia nervosa (AN) e a bulimia nervosa (BN). O objetivo desta pesquisa é investigar como pacientes atendidos em um ambulatório de saúde mental vivenciaram o aparecimento de sintomas de TA. Foram convidados a participar voluntariamente deste estudo dez pacientes em atendimento junto ao Hospital das Clínicas de uma cidade do oeste paulista. Seis concordaram em participar. Para a coleta de dados, foi utilizada a entrevista semiestruturada. Os depoimentos revelam dois fatores que favoreceram o aparecimento de TA, segundo a ótica das entrevistadas: conflitos em relacionamentos interpessoais e pressão social para emagrecimento/estigmatização. Possivelmente, influências socioculturais permeiam as significações atribuídas pelas pacientes à sua imagem refletida no espelho, contribuindo para o aparecimento de distorções na percepção do peso e forma corporal. Os resultados deste estudo sugerem ainda que, muitas vezes, a tomada de consciência do problema demora a ocorrer. Assim, o envolvimento de familiares e o fornecimento de informações e orientações sobre a natureza do transtorno são essenciais no escopo das intervenções para tratamento do problema. Supõe-se que programas de natureza preventiva, destinados à melhoria do funcionamento interpessoal dos adolescentes, poderiam minimizar o risco do aparecimento de TA. Este estudo pretende contribuir com ações dessa natureza, além de subsidiar equipes multiprofissionais no atendimento aos pacientes.
\end{abstract}

Palavras-chave: transtornos psicológicos; transtorno alimentar; imagem corporal; anorexia nervosa; bulimia nervosa.

\begin{abstract}
The incidence of eating disorders (ED) in the population has been increasing steadily. Among the different issues related to food, the highlights are Anorexia Nervosa (AN) and Bulimia Nervosa (BN). The objective of this research is to investigate how patients treated at an outpatient mental health experienced the onset of symptoms of ED. Ten patients in care at the 'Hospital das Clínicas' of the West of São Paulo City were invited to participate, voluntarily in this study,. Six of them agreed to participate. For data collection, we used the semi-structured interview. Reports reveal two factors that favored the appearance of ED, according to the interviewees: conflicts in interpersonal relationships and social pressure for slimming/stigmatization. Possibly, sociocultural influences permeate the meanings attributed by patients to their mirror image, contributing to the emergence of distortions in the perception of body weight and shape. The results of this study also suggest that often the awareness of the problem has a delay to happen. Thus, the involvement of family members
\end{abstract}

Artigo Original

Gabriela Andrea Leite Gonzalez ${ }^{(1)}$ Ernindo Sacomani Junior ${ }^{(2)}$ Regina de Cássia Rondina ${ }^{(3)}$

1) Aprimoramento em Saúde Mental em Terapia Ocupacional no Instituto de Psiquiatria - Hospital das Clinicas da Universidade de São Paulo, São Paulo.

\footnotetext{
2) Prof. Ms Faculdade de Medicina de Marilia (Famema).

3) Prof ${ }^{\mathrm{a}}$ Assistente Doutora Departamento de Psicologia e Educação pela Universidade Estadual Paulista (Unesp, Marilia).
}

Recebido em: 01/08/2013 Revisado em: 18/11/2014 Aceito em: 25/11/2014 
and the provision of information and guidance on the nature of the disorder are essential in the scope of interventions for treating the problem. It is assumed that preventive programs aimed at improving interpersonal functioning of adolescents, could minimize the risk of developing ED. This study aims to contribute to such actions, in addition to supporting multiprofessional teams in patient care.

Keywords: psychological disorders; eating disorders; body images; anorexia nervosa; bulimia nervosa.

\section{Resumen}

La incidencia de los trastornos de la conducta alimentaria en la población ha crecido en los últimos años. Entre los distintos problemas relacionados con la alimentación destacan la anorexia nerviosa (AN) y la bulimia nerviosa (BN). El objetivo de este estudio es investigar cómo los pacientes atendidos en un ambulatorio de salud mental han experimentado la aparición de sintomas de trastornos de la conducta alimentaria. Diez pacientes del Hospital de las Clínicas de una ciudad del Oeste de São Paulo fueron invitados a participar en este estudio. Seis estuvieron de acuerdo en participar. Para la recogida de datos se utilizó una entrevista semiestructurada. Las respuestas revelan dos factores favorecedores de la aparición de los trastornos de la conducta alimentaria desde la perspectiva de los entrevistados: los conflictos en las relaciones interpersonales y la presión social para la pérdida de peso/estigmatización. Posiblemente las influencias socioculturales impregnan los significados atribuidos por los pacientes a su propia imagen reflejada en el espejo, lo que contribuye a la aparición de distorsiones de la percepción del peso y forma corporal. Los resultados de esta investigación también indican que a menudo la toma de consciencia del problema tarda en ocurrir. Por lo tanto, la participación de los familiares y la entrega de información y orientaciones acerca de la naturaleza del trastorno son esenciales en el alcance de las intervenciones para el tratamiento del problema. Se supone que los programas de prevención dirigidos a mejorar el funcionamiento interpersonal de los adolescentes podrían minimizar el riesgo de aparición de trastornos de la conducta alimentaria. Este estudio tiene como objetivo contribuir a este tipo de acciones, además de apoyar a los equipos multidisciplinarios en la atención a los pacientes.

Palabras clave: trastornos psicológicos; trastornos de la alimentación; imagen corporal; anorexia nerviosa; bulimia nerviosa.

\section{Résumé}

L'incidence des troubles d'alimentation dans la population augmente progressivement. Entre les différentes questions liées à l'alimentation, on peut démarquer l'anorexie mentale et la boulimie. L'objectif de cette recherche est d'étudier la façon dont les patients traités dans une clinique de santé mentale ont connu l'apparition des symptômes des troubles d'alimentation. Dix patients en soins à l'hôpital das Clinicas dans une ville de Oeste Paulista ont été invités à participer à cette étude. Parmi ces invitations, six personnes ont accepté de participer. Pour la collecte des données, on a utilisé une interview semi-structurée. Les rapports révèlent deux facteurs qui ont favorisé l'apparition des troubles d'alimentation, d'après les patients interrogées: les conflits dans les relations interpersonnelles et la pression sociale pour la perte de poids / stigmatisation. C'est possible que le sens attribué par les patients à sa propre image reflétée dans le miroir soit imbu d'influences socioculturelles, ce qui contribue à la manifestation de distorsions dans la perception du poids et de la forme corporels. Les résultats de cette étude suggèrent également que, parfois, la prise de conscience du problème se produit en retard. Ainsi, la participation des membres de la famille et la fourniture d'informations et des conseils sur la nature de la maladie sont essentiels dans le cadre des soins pour traiter le problème. On présume que les programmes de prévention, visant à améliorer le fonctionnement interpersonnel des adolescents pourraient réduire le risque de l'apparition des troubles de l'alimentation. Cette étude tend à contribuer à ces actions et aussi de soutenir des équipes multidisciplinaires pour soigner les patients.

Mots-clés: troubles psychologiques; troubles d'alimentation; l'image corporelle; l'anorexie mentale; la boulimie.

O transtorno alimentar (TA) caracteriza-se por perturbações no comportamento alimentar. Dentre os diferentes quadros psicopatológicos relacionados à alimentação, destacam-se a anorexia nervosa (AN) e a bulimia nervosa (BN). A anorexia nervosa é definida como um transtorno da alimentação, caracterizado pela perda de peso autoinduzida, intencional e mantida pelo paciente, perturbação na forma de vivenciar o baixo peso; influência indevida do peso sobre a autoavaliação; e negação do baixo peso, podendo ou não haver comportamentos de compulsão alimentar e purgação (APA, 2002; OMS, 2009). Por outro lado, a bulimia nervosa consiste em: episódios recorrentes de compulsão alimentar (com frequência dos episódios, em média, de pelo menos duas vezes na semana, por três meses), métodos compensatórios para prevenção de ganho de peso (indução de vômitos, uso de laxantes, entre outros) e influência indevida do peso/forma corporal sobre a autoavaliação (APA, 2002).

AAN e BN podem acarretar uma variedade de prejuízos à saúde. É bastante comum, por exemplo, o aparecimento de desnutrição em graus variáveis, acompanhada de modificações endócrinas e metabólicas secundárias, além de perturbações das funções fisiológicas (OMS, 2009) e limitações graves na sua funcionalidade (Gonzaléz, Adierna, Aróstegui, \& Horcajo, 2001; Morais, 2006; OMS, 2003). É também bastante frequente o aparecimento de TA em comorbidade com outros transtornos psiquiátricos, como transtornos de humor e de ansiedade (APA, 2002). Há indícios de que a incidência do problema vem aumentando progressivamente. Pesquisas demonstram um aumento do número de pessoas com TA em etnias minoritárias e em 
países não ocidentais (Jacobi, Hayward, Zwaan, Kraemer, \& Agras, 2004; Lee, Chan, \& Hsu, 2003). Parece haver um consenso, atualmente, de que o problema não é exclusivo do mundo ocidental, acometendo a população de países com diferentes graus de desenvolvimento (Alves, Pinto, Alves, Mota, \& Leirós, 2009; Oliveira \& Hutz, 2010; Pinzon \& Nogueira, 2004). Acredita-se, contudo, que a sintomatologia desenvolvida pelas pacientes adquire configurações particulares segundo diferentes culturas (Alves et al., 2009; Oliveira \& Hutz, 2010).

A literatura sobre o assunto sugere que o TA pode ser desencadeado por múltiplas causas. Barlow e Durand (2008), por exemplo, afirmam que a etiologia do problema só pode ser adequadamente entendida através de uma visão integrada e multidimensional. Ou seja, fatores de natureza biológica, psicológica e psicossocial podem interagir, contribuindo para o aparecimento do transtorno alimentar. Com relação a fatores psicológicos, observações clínicas indicam que muitas mulheres jovens com transtorno alimentar apresentam baixa autoestima, por se sentirem menos donas das próprias decisões. Além disso, em geral, também demonstram ter atitudes mais perfeccionistas e ansiedade acentuada. Quando esse perfeccionismo é dirigido para a manutenção da estética, associada à percepção distorcida da imagem corporal, pode se converter em um poderoso gatilho, contribuindo para desencadear os comportamentos típicos observados no transtorno alimentar. A adoção de comportamentos purgativos geralmente traz uma falsa sensação de alívio, o que acaba reforçando negativamente tais comportamentos. Isto cria um círculo vicioso, de maneira que a tendência é a repetição do comportamento que dá prazer ou alívio em relação à ansiedade (Barlow \& Durand, 2008).

Segundo a literatura especializada, fatores de natureza psicossocial, como a qualidade da interação com amigos ou colegas, influenciam as atitudes de pessoas de um grupo. Estudos mostram que determinados grupos ou contextos sociais tendem a partilhar das mesmas atitudes quanto à imagem corporal, restrição dietética e importância atribuída às tentativas para perder peso. Em contextos nos quais pressões para se manter o corpo sempre magro, como entre grupos de bailarinos ou modelos, as atitudes grupais podem influenciar o desencadeamento do transtorno alimentar com mais frequência. A dinâmica de interação familiar também pode contribuir para o surgimento do problema. A família da anoréxica, em geral, é bem-sucedida, preocupa-se com as aparências e deseja sempre manter a harmonia; para isso, nega ou ignora conflitos existentes nas relações familiares (Barlow \& Durand, 2008). No tocante aos fatores de natureza sociocultural, para Goldenberg (2005), na sociedade contemporânea, o culto obsessivo ao corpo aprisiona as mulheres, levando-as a viverem em busca do padrão magro de beleza. A autora demonstrou que as mulheres dos anos oitenta promoveram um movimento no sentido da libertação de seus corpos em relação à sexualidade e às roupas que deveriam utilizar. Atualmente, ocorre o contrário, pois está acontecendo uma padronização dos corpos e um processo no qual as mulheres estão preocupadas em se manterem jovens e magras, e para atingirem esta finalidade, utilizam vários recursos, como dietas, ginástica e cirurgias plásticas. Segundo Barlow e Durand (2008), para muitas mulheres, parecer bela perante a sociedade é mais importante do que ser saudável. Para mulheres jovens que vivem em ambientes competitivos, a autoestima, a felicidade e o sucesso podem ser determinados em grande parte pela sua imagem, pelas medidas corporais e pela porcentagem de gordura no corpo. A cultura impõe a magreza e hábitos de fazer dieta, o que pode se tornar o primeiro passo perigoso para a $\mathrm{AN}$ e $\mathrm{BN}$.

Aspectos socioculturais podem influir decisivamente na relação do indivíduo com o próprio corpo e, consequentemente, no aparecimento de transtornos a ela associados. A obesidade tem sido considerada uma condição estigmatizada pela sociedade e associada a características negativas, favorecendo discriminações e sentimentos de insatisfação (Almeida, Santos, Pasian, \& Loureiro, 2005). Indivíduos com sobrepeso e obesos são considerados, pela sociedade contemporânea, maus gestores de si, moralmente fracos, sem autocontrole, preguiçosos e/ou desleixados. Já a imagem de um corpo magro é relacionada a indivíduos de sucesso, que são capazes de ter um maior controle sobre seu comportamento alimentar (Santos, 2008; Sibilia, 2004). Assim, uma característica importante no TA é o modo pelo qual o paciente vivencia ou lida com a questão do peso corporal. Em geral, há uma autoavaliação centrada na forma física. Essa visão costuma provocar a negação dos riscos associados ao emagrecimento excessivo, desencadeando a busca desenfreada pela magreza (Peres \& Santos, 2006). Nos transtornos psicológicos em geral, ocorrem alterações das funções psíquicas. Uma das principais alterações presentes em pacientes com TA é a distorção perceptiva. Assim, é de se supor que as distorções na percepção da forma e peso corporal, de alguma forma, estão entrelaçadas à construção da imagem corporal pelo indivíduo.

A imagem corporal refere-se, de maneira geral, à representação mental que cada indivíduo possui acerca de seu próprio corpo. [...] A qualidade da imagem corporal de um indivíduo se encontra intimamente associada à consistência de seu sistema de identidade. Esse sistema, por sua vez, é influenciado pelas representações das primeiras relações de objeto elaboradas durante a infância e pelas experiências emocionais de relacionamento com o corpo do outro e com o próprio corpo. (Peres \& Santos, 2006, p. 362) 
A literatura como um todo, contudo, sugere que a construção da imagem corporal pode ser influenciada por um conjunto integrado de fatores no decorrer do ciclo de vida.

Alguns fatores podem contribuir para o aparecimento de problemas na imagem corporal na infância, como, o índice de massa corporal (IMC); a índole ou temperamento; as influências socioculturais; os pais; o grupo de relacionamento pessoal; os meios de comunicação e os brinquedos. (Damasceno et al., 2006, p. 83)

A imagem corporal não consiste em uma imagem no sentido próprio da palavra. Ela engloba imagens e representações mentais; portanto, não é um espelho fiel de nosso corpo ou resultado de familiarização este. Cada pessoa elabora ao seu modo a imagem do próprio corpo. Assim, essa imagem não é apenas consciente; ela é construída também, parcialmente, tomando como referência o corpo de outras pessoas. Constitui uma unidade adquirida gradualmente, podendo ser construída e reconstruída, em um processo continuo (Menédez, 2007).

Influem no aparecimento e evolução do TA, portanto, numerosas questões biológicas, psicológicas e socioculturais. $\mathrm{O}$ volume de trabalhos enfocando o assunto vem aumentando nas últimas décadas. Contudo, é possível afirmar que ainda hoje são necessárias mais pesquisas para o embasamento das ações preventivas e terapêuticas. A literatura denota relativa escassez de trabalhos contendo relatos "à viva voz" de pacientes com TA sobre suas vivências e o sofrimento psíquico associado ao aparecimento do problema. Pretende-se, então, contribuir com o trabalho de equipes multiprofissionais no atendimento a pacientes com transtornos psicológicos, e também contribuir com o estabelecimento de programas preventivos e/ou terapêuticos.

\section{Método}

Este estudo investiga como se dá o aparecimento dos sintomas de transtornos alimentares (TAs) e como pacientes vivenciam questões relacionadas à construção de sua imagem corporal. Buscou-se descrever e compreender, segundo a ótica dos participantes, o sofrimento psíquico associado ao aparecimento do problema, bem como os significados atribuídos na relação com o próprio corpo e a busca do corpo ideal ou perfeito.

Optou-se por desenvolver uma pesquisa de natureza qualitativa, uma vez que essa abordagem permite o entendimento das significações atribuídas por um sujeito ou grupo ao tema em questão (Canzonieri, 2010). As características desse tipo de estudo vão ao encontro dos objetivos propostos, permitindo a imersão do pesquisador na realidade estudada, para maior compreensão do assunto: "O pesquisador faz parte do processo de pesquisa e suas manifestações, observações, percepções e conhecimento são muito importantes para a realização da mesma" (Canzonieri, 2010, pp. 38-39). Trata-se de uma pesquisa de natureza exploratória, com desenho metodológico sob a forma de um estudo de caso (Canzonieri, 2010); enfoca um único caso, representado por um grupo de pacientes submetidas a um programa multidisciplinar de tratamento.

\section{Instituição Alvo}

O trabalho foi realizado junto ao ambulatório de Saúde Mental do Hospital das Clínicas de uma cidade do interior paulista, que disponibiliza tratamento multidisciplinar para transtornos alimentares. Os profissionais que participam da equipe multiprofissional são: médicos psiquiatras, endocrinologistas, psicólogos, nutricionistas e assistentes sociais - vale ressaltar que o programa ainda não conta com terapeutas ocupacionais. $\mathrm{O}$ ambulatório atende à população do Sistema Único de Saúde (SUS) da região. O programa funciona semanalmente, sendo realizada uma primeira consulta com os pacientes psiquiátricos individualmente, para realização do diagnóstico clínico. Em seguida, o paciente é encaminhado para uma avaliação nutricional, psicológica e endocrinológica, e a família é encaminhada para uma avaliação social. Após esses procedimentos, o diagnóstico é efetuado e o plano de tratamento é traçado. Os casos mais graves (como aqueles nos quais há recusa em aceitar a alimentação prescrita pelo nutricionista, há desnutrição grave; os pacientes apresentam vômitos excessivos e frequentes, ou quando existe o risco de suicídio), podem ser encaminhados para internação. Para ingresso no serviço, os pacientes são encaminhados por diversos serviços públicos de uma cidade do oeste paulista e região.

O atendimento psicoterápico é realizado de duas formas: individualmente (sendo efetuada uma consulta entre paciente e o profissional/terapeuta) e em grupos, com o psicólogo, uma vez por semana, aos quais os pacientes são encaminhados de acordo com sua necessidade. As consultas com o nutricionista e com o endocrinologista têm a duração aproximada de uma hora e são efetuadas uma vez por mês. É realizada uma discussão integrada com os profissionais envolvidos nos atendimentos, coordenada pelo médico psiquiatra responsável pelo programa.

A maior parte dos pacientes é considerada crônica, e os tratamentos duram, em média, um ano. À época em que se deu esta pesquisa, frequentavam o programa aproximadamente cem pacientes, e alguns deles já se 
encontravam em processo de alta. A maioria da clientela era composta por mulheres com idade compreendida entre treze e vinte e cinco anos.

\section{O Grupo Pesquisado}

Os participantes deste estudo foram pacientes em atendimento regular junto ao programa, no período compreendido entre setembro de 2010 e março de 2011. Os sujeitos foram pré-selecionados após o acesso aos prontuários dos pacientes em atendimento, com o auxílio da equipe do hospital. Foram escolhidos os que se enquadravam nos seguintes critérios: apresentar registro descritivo (no prontuário) de sintomas relacionados a distorções na percepção da imagem corporal, estar frequentando regularmente as sessões de tratamento no ambulatório do hospital e ter idade entre 17 e 28 anos. Dentre os que preencheram esses critérios, foram selecionados, aleatoriamente, dez pacientes, os quais foram convidados a participar voluntariamente da pesquisa, mas apenas seis concordaram.

\section{Instrumentos de Coleta de Dados}

Para levantamento das vivências e percepções dos participantes, foi utilizada a entrevista semiestruturada. Essa estratégia foi escolhida porque possibilita o levantamento de informações de forma mais aberta e as respostas não são condicionadas a um padrão (Manzini, 2004). Há um roteiro com perguntas previamente estabelecidas, mas se estabelece uma conversa continuada entre pesquisador e participante, sendo dirigida pelo pesquisador (Canzonieri, 2010). As entrevistas tiveram como finalidade geral investigar como pacientes com transtorno alimentar vivenciaram o início de distorções na percepção corporal, entre outros aspectos. O roteiro foi elaborado especificamente para este estudo.

\section{Procedimentos}

O projeto de pesquisa que embasou este trabalho foi submetido ao Comitê de Ética em Pesquisa de uma das unidades da Universidade Estadual Paulista (UNESP), através do processo número 2118/2010. Após aprovação, foram levantados os prontuários de pacientes, que iniciaram o atendimento a partir de setembro de 2010. Os pacientes selecionados foram convidados a participar do estudo voluntariamente. Aqueles que concordaram receberam um Termo de Consentimento Livre e Esclarecido - TCLE. Após assinatura do termo, as entrevistas foram realizadas e gravadas.

Os depoimentos foram transcritos e analisados com base na abordagem proposta por Minayo (1993). Após repetidas leituras, foram selecionados os trechos mais significativos dos relatos. Em seguida, os trechos foram agrupados sob a forma de núcleos temáticos, aqui caracterizados como "tópicos". Os tópicos abordam temas diretamente relacionados aos objetivos da pesquisa. Finalmente, foram elaboradas categorias de tópicos, de modo a possibilitar uma descrição compreensiva do assunto em questão.

\section{Resultados e Discussão}

Da análise das entrevistas, emergiram as seguintes categorias:

1. Momento do ciclo de vida em que os sintomas foram percebidos/Idade de aparecimento dos sintomas. Descreve as percepções das entrevistadas sobre o momento em que começaram a vivenciar os sintomas relacionados ao transtorno alimentar.

2. Fatores que motivaram o aparecimento dos sintomas, segundo a percepção das entrevistadas. Essa categoria descreve as percepções das entrevistadas sobre os fatores que favoreceram o aparecimento dos sintomas relacionados ao transtorno alimentar.

3. A relação com o espelho: conflitos relacionados à percepção da imagem corporal. Apresenta relatos sobre as vivências das pacientes e os sentimentos despertados diante de sua imagem refletida no espelho. Busca descrever, ainda, os comportamentos associados à percepção da sua imagem corporal.

4. A relação com a comida e significações associadas ao corpo. Essa categoria apresenta os relatos das entrevistadas sobre as vivências e sentimentos associados ao tratamento para o TA, destacando os aspectos nutricionais. Descreve, segundo a ótica das entrevistadas, a dimensão simbólica atribuída à sua imagem corporal no cotidiano.

5. Ter um TA, segundo a ótica das entrevistadas. Apresenta as falas das entrevistadas em relação aos seus sentimentos e experiências, buscando descrever como é, para elas, conviver com o transtorno alimentar em suas vidas.

\section{Momento do Ciclo de Vida em que os Sintomas Foram Percebidos/Idade de Aparecimento dos Sintomas.}

$\mathrm{O}$ conjunto dos relatos sugere que para a maioria das entrevistadas, o aparecimento dos sintomas se deu entre o início da adolescência ou início da juventude.

Quando eu tinha uns 14 anos mais ou menos e eu era meia gordinha. (T)

Contudo, há exceções:

Faz quatro anos, e eu comecei a me sentir gorda, aí coloquei na cabeça, comecei a fazer regime, comecei a 
emagrecer muito e mesmo assim tava me achando gorda, e provocando vômito junto. (R)

Os relatos das entrevistadas, como um todo, são compatíveis com o que prevê a literatura. Principalmente durante a adolescência ou no começo da idade adulta, tendem a aparecer as preocupações relacionadas à estética e à necessidade de emagrecer, na maioria dos casos de TA, relacionados à $\mathrm{AN}$ e $\mathrm{BN}$.

Entre as adolescentes, o medo intenso de engordar favorece o desenvolvimento de comportamentos de risco para o transtorno alimentar, como a realização de dietas extremadas, atividades físicas em excesso, utilização de medicamentos diuréticos, laxantes e anorexígenos, e provocação de vômitos (Oliveira \& Hutz, 2010). É importante notar que, durante a puberdade, ocorre uma série de mudanças físicas e psicológicas, o que, em geral, favorece que as adolescentes aumentem sua gordura corporal. Isto pode acabar acarretando mudanças não apenas na aparência física, mas no sentimento que elas possuem em relação à sua imagem corporal (Damasceno et al., 2006).

\section{Fatores que Motivaram o Aparecimento dos Sintomas, Segundo a Percepção das Entrevistadas}

As entrevistas revelam que pressões de familiares e de colegas (representadas principalmente por comentários pejorativos sobre a aparência pessoal da paciente durante a adolescência), foram percebidas pelas pacientes como associadas ao momento de início do problema. Também vivências estressantes, como sofrer bullyng na escola, foram relatadas por elas:

(...) todo mundo me zuava comigo, até em casa também me chamavam de gordinha em casa... acho que eu devia emagrecer, aí eu fazia regime e não emagrecia, eu achei que se eu vomitasse ou ficasse sem comer eu emagrecia... ai eu acabei emagrecendo mesmo, de verdade, ai eu continuei. (T)

O pessoal chegava em mim e falava, olha a barriguinha dela, ta gordinha. E eu fui pondo na minha cabeça que eu precisava emagrecer. Ai eu não comia. (T)

A literatura especializada no assunto ressalta o papel da rejeição sofrida no âmbito das relações interpessoais como um fator que pode favorecer o aparecimento dos sintomas:

É notado o estigma social perante o excesso de peso, como foi constatado nos apelidos pejorativos pelos quais os adolescentes obesos são frequentemente chamados. Essas situações acabam por retirar do adolescente obeso a sua própria identidade, o que às vezes lhe dá a sensação de estranheza de si próprio. O adolescente obeso começa a perceber que seu corpo não corresponde ao idealizado para si e também para o grupo de iguais e, via de regra, é através da comparação com os outros adolescentes que ele começa a assumir um importante papel de insatisfação com o próprio corpo e rejeição por parte da turma. (Ferriani, Dias, Silva, \& Martins, 2005, p. 32)

Durante a adolescência em geral, os pares, o entorno social e a própria mídia podem favorecer o aparecimento de sentimentos de insatisfação corporal entre os adolescentes, até mais do que os pais. $\mathrm{O}$ reforço social exercido pela família, pelo grupo de pares e pela mídia em adolescentes e adultas jovens para ter o corpo magro relaciona-se à presença de sintomas bulímicos e prediz o início de sintomas nesta população (Oliveira \& Hutz, 2010). Questões psicossociais, portanto, parecem ser fortes desencadeantes para o problema. Contudo, para alguns especialistas no assunto, a dinâmica de interação familiar pode contribuir fortemente para o surgimento de problemas como a anorexia nervosa. A "típica" família da anoréxica é bem sucedida, tem boa conduta, preocupa-se com as aparências e deseja sempre manter a harmonia. Para atingir esses objetivos, os familiares frequentemente negam ou ignoram os conflitos ou sentimentos negativos e tendem a atribuir seus problemas a outras pessoas. Esses conflitos muitas vezes expressam a necessidade que a família tem de atingir o perfeccionismo. Isso pode se tornar evidente, por exemplo, quando imensa importância é dada para os fatores estéticos (Barlow \& Durand, 2008).

Neste estudo, conflitos interpessoais, em geral, também foram percebidos pelas entrevistadas como eventos estressantes, que contribuíram para o aparecimento dos sintomas.

(...) quando houve uma separação entre eu e meu atual marido de hoje, aí foi que eu entrei nessa anorexia. (V)

Episódios estressantes do ciclo vital que envolvem transições como mudança de casa, puberdade, gravidez, divórcio, separações, entre outros fatores, podem contribuir para o aparecimento do problema (Silva, 2005). No entanto, é importante não perder de vista que cada trajetória é única. Conforme foi mencionado, a literatura contemporânea sugere que o aparecimento e a evolução do TA devem ser compreendidos através de uma visão multidimensional e integrada. Determinantes biológicos, psicológicos e sociais estão em constante interação e podem influenciar no aparecimento dos sintomas. Assim, características individuais podem conferir ao sujeito maior vulnerabilidade ao estresse e, consequentemente, aumentar a probabilidade de aparecimento do TA (Barlow \& Durand, 2008).

Em suma, os relatos das entrevistadas revelaram a 
percepção de dois fatores motivacionais associados ao aparecimento dos sintomas: conflitos nos relacionamentos interpessoais (em especial com familiares), além de pressões para emagrecer e/ou gozações por parte de terceiros.

\section{A Relação com o Espelho: Conflitos Relacionados à Imagem Corporal}

Os depoimentos revelam que muitas vezes, sentimentos como depressão, tristeza e raiva aparecem no momento em que as pacientes observam sua imagem refletida no espelho, sugerindo conflitos relacionados principalmente à autoestima:

(...) eu me achava horrível, ficava triste o dia inteiro ruim horrível. Me sinto gorda, sinto raiva, não gosto de mim. (R)

(...) não me vejo magra, me sinto triste sabe; quando eu me olho no espelho, me vejo gorda, eu me sinto gorda, eu nem gosto de olhar no espelho, eu me sinto deprimida, aí eu nem olho. (T)

(...) quando me olho no espelho passa raiva, penso por que esse problema? Porque não foi de novo a depressão ou então uma raiva de momento, uma rebeldia, por que justo esse problema que é um dos mais difíceis de resolver? (J)

\section{(...) Eu sinto muita raiva. (T)}

Conforme discutido anteriormente, questões associadas à percepção da imagem corporal constituem um aspecto central na problemática do transtorno alimentar. $\mathrm{O}$ conceito de imagem corporal envolve três componentes:

- o perceptivo, que se relaciona com a precisão da percepção da própria aparência física, envolvendo uma estimativa do tamanho corporal e do peso;

- o subjetivo, que envolve aspectos como satisfação com a aparência, nível de preocupação e ansiedade a ela associada;

- o comportamental, que focaliza as situações evitadas pelo indivíduo por experimentar desconforto associado à aparência corporal. (Saikali, Soubhia, Scalfaro, \& Cordás, 2004, p 164)

Assim, o processo de construção da imagem corporal pode ser influenciado por numerosas questões de natureza biológica, psicológica e sociocultural.

A partir de resultados de estudos disponíveis, é possível afirmar que as experiências afetivas de um indivíduo desempenham um papel mais determinante para a constituição de sua imagem corporal do que as percepções objetivas referentes à sua forma física. Assim, é possível dizer que a imagem corporal não está vinculada ao corpo real, mas sim ao corpo simbólico, produto das experiências de trocas afetivas vivenciadas nos diferentes estágios do ciclo vital. (Peres \& Santos, 2006, p. 362)

A percepção da imagem corporal, os sentimentos de baixa autoestima e a própria relação das entrevistadas com o espelho possivelmente são permeadas por conflitos relacionados aos padrões impostos socialmente:

Percebe-se que o mundo social claramente discrimina os indivíduos não atraentes, numa série de situações cotidianas importantes. Pessoas julgadas pelos padrões impostos como atraentes parecem receber mais apoio e encorajamento no desenvolvimento das funções, fazendo com que se sintam socialmente seguros e competentes; por outro lado, indivíduos considerados não atraentes, estão mais sujeitos a encontrar ambientes sociais que variam do não-responsivo ao rejeitador e que desencorajam o desenvolvimento de habilidades sociais e de um autoconceito favorável. (Saikali et al., 2004, p. 165)

Chama atenção o fato de, paradoxalmente, algumas declararem gostar de se olhar no espelho.

Eu até gosto de me olhar no espelho. Parece que você não se vê no espelho, parece que você vê outra pessoa, Sinto necessidade de olhar no espelho, se eu for sair eu preciso me olhar. (V)

No entanto, essa aparente ambiguidade ou contradição na relação com o espelho pode estar também diretamente atrelada às distorções perceptivas em relação ao próprio corpo.

As pacientes com TA podem apresentar diferentes padrões de comportamento em relação à exposição de seu corpo. Algumas evitam olhá-lo e outras o examinam compulsivamente. A verificação compulsiva aumenta a insatisfação com o formato corporal através da atenção seletiva para as partes do corpo insatisfatórias sob a ótica da paciente, o que reforça o pensamento de que ela é gorda e imperfeita, mantendo a insatisfação e a preocupação excessiva com a aparência. (Duchesne \& Freitas, 2011, p. 403)

É possível que, em alguns casos, a verificação compulsiva do próprio corpo diante do espelho acabe por criar um círculo vicioso, contribuindo com a perpetuação 
dos sintomas.

Além disso, é importante mencionar que, neste trabalho, cada paciente se encontrava em um momento diferente quando começou a apresentar os sintomas.

A imagem corporal refere-se, de maneira geral, à representação mental que cada indivíduo possui acerca de seu próprio corpo. Moldada pela relação que o sujeito estabelece consigo mesmo e com seu ambiente, essa representação é construída e reconstruída incessantemente ao longo da vida. (Peres \& Santos, 2006, p. 362)

As entrevistadas deste estudo podem experimentar percepções diferentes ao se enxergarem refletidas no espelho, devido às diferentes vivências que tiveram no decorrer de suas vidas:

A construção da imagem corporal é resultado das relações consigo mesmo e com os outros, por isso é algo que implica um esforço dinâmico e contínuo. Ela não se trata de uma imagem no sentido próprio da palavra. Cada pessoa constrói a imagem de seu corpo, a sua maneira, em função dos mecanismos de sua personalidade e de todas as suas vivências passadas e presentes. É uma unidade interligada, onde a alteração de uma parte levará a alteração de toda a imagem corporal, podendo ser alterada e destruída. A imagem corporal inclui imagens e representações mentais, e não é apenas consciente, pois também toma como referência o corpo do outro. (Menédez, 2007, p. 2)

Contudo, o conjunto dos relatos sugere que a maioria das pacientes experimenta sentimentos extremamente negativos associados à percepção do corpo refletido no espelho. Os depoimentos sugerem que essas vivências podem ser perpassadas por complexas questões de natureza biopsicossociocultural.

\section{A Relação com a Comida e as Significações Associadas ao Corpo}

Ainda podemos observar, com os relatos, os conflitos relacionados à alimentação e ao peso.

(...) não consigo seguir a dieta que a nutricionista passa pra mim... por mais que ela me passe um cardápio, eu chego em casa e guardo na gaveta... a minha dieta é completamente de maçã. Só como quando tenho fome. (J)

Se eu não comer, eu me sinto feliz. (T)

Comia, começava a passar mal e vomitava. (V)
Os conflitos relacionados à alimentação podem desencadear comportamentos que oferecem riscos à saúde: "Com a dificuldade de adquirir o peso baixo desejado por meio de dietas saudáveis e exercícios físicos, as pesquisas mostram que muitas adolescentes passam a desenvolver práticas inadequadas de controle de peso" (Oliveira \& Hutz, 2010, p. 578). Um conjunto de fatores psicossociais pode acentuar o problema: "É notável também o crescente número de sites que incentivam as adolescentes a desenvolver ou manter o transtorno alimentar, ensinando técnicas de purgação e "truques" supostamente milagrosos para atingir um estado severo de emagrecimento" (Oliveira \& Hutz, 2010, p. 577). Os relatos das entrevistadas no presente trabalho são compatíveis com o que prevê a literatura. Na maioria dos relatos, a preocupação com questões relacionadas à estética aparece como prioridade na vida das entrevistadas. As pacientes afirmam fazer o que for necessário para alcançar seus objetivos, relacionados ao ideal de beleza corporal.

(...) significa tudo, pra eu me sentir bem, fico sem comer mesmo... meu objetivo mesmo é emagrecer mesmo, ficar com peso baixo mesmo, se eu estiver com peso baixo eu sei que eu to magra, agora se eu tiver com peso a mais eu sei que eu to gorda. (T)

É importantíssimo observar que nos transtornos psicológicos em geral, ocorrem alterações das funções psíquicas. As distorções na percepção da forma e do peso corporal são características essenciais, observadas principalmente em quadros de $\mathrm{AN}$ e $\mathrm{BN}$. No tocante à anorexia nervosa, em especial, os conflitos relacionados às distorções na percepção do peso e forma corporal estão diretamente atrelados ao problema:

Uma característica psicopatológica importante na anorexia nervosa é a severa perturbação no modo de vivenciar o peso corporal. Motivada pela auto avaliação centrada na forma física, essa perturbação provoca a negação dos riscos associados ao emagrecimento excessivo, fomentando, assim, a busca desenfreada da magreza. (Peres \& Santos, 2006, p. 362)

Como mencionado anteriormente, normas socioculturais têm perpetuado o estereótipo da associação entre magreza e atributos positivos nas últimas décadas, principalmente entre as mulheres. Para elas, o desejo de melhorar a aparência física, diminuir o descontentamento com o corpo e deixar de ser alvo de discriminações parecem ser as principais motivações para a mudança quanto ao tamanho e à forma corporal (Almeida et al., 2005). Neste estudo, fica evidente a forma como o corpo é percebido pelas pacientes 
e os significados atribuídos a ele. As falas deixam também transparecer a relação disso com o medo do distanciamento das normas de beleza, bem como os esforços / sacrifícios efetuados na tentativa de transformá-lo.

\section{(...) vivo em função dele [do corpo]. (R)}

Meu corpo é muito importante. (V)

É importante destacar a forte dimensão simbólica associada ao assunto. Ou seja, o discurso das entrevistadas permite inferir a dimensão simbólica atribuída ao ideal de perfeição corporal que permeia os esforços na busca pelo corpo esbelto. Em última instância, possivelmente os depoimentos se traduzam também como reflexos de construções socioculturais associadas ao assunto.

Crenças culturais determinam normas sociais na relação com o corpo humano. Práticas de embelezamento, manipulação e mutilação, fazem do corpo um terreno de significados simbólicos. Mudanças artificiais em seu formato do corpo, tamanho e aparência são comuns em todas as sociedades e têm uma importante função social. Elas comunicam a informação sobre a posição social do indivíduo e, muitas vezes, demonstram um sinal de mudança em seu status social. (Saikali et al., 2004, pp. 164-165)

O corpo se tornou um dos valores mais importantes no atual momento histórico. A indústria da estética corporal é hoje um dos maiores mercados da sociedade de consumo. O avanço da tecnologia da beleza, através da mídia, modela subjetividades e impulsiona a indústria da magreza. A publicidade aumenta o desejo de cada um de ter um corpo semelhante ao que ela sugere de forma repetitiva, portanto, também o de poder transformá-lo. Em consequência, os indivíduos veem o corpo como instrumento que deve ser perfeito e passível de constante remodelagem. (Oliveira \& Hutz, 2010, p. 577)

\section{Ter um Transtorno Alimentar, Segundo a Ótica das Entrevistadas}

Alguns depoimentos revelam claramente que muitas vezes, a tomada de consciência do problema demora a ocorrer.

(...) quando eu passei de 38 para 36 (no número do manequim), quando diminuiu tudo, pensei,' eu até queria diminuir', aí eu pensei, 'nossa consegui', mas pensei alguma coisa, aí eu mudei, que eu vi que mudou... a academia não foi... ai eu falei, 'ah, comendo eu já não tava'. Foi aí que eu percebi. (T)
Aparecem ainda sentimentos negativos com relação ao transtorno alimentar e como cada uma o percebe/significa no seu dia-a-dia. Os depoimentos sugerem sensações de estranheza e/ou de "não ser normal".

(...) é difícil, totalmente difícil, não consigo sair dessa doença logo; eu queria sair, eu queria ser uma pessoa normal. (T)

Fica evidente, em alguns relatos, a negação e/ou a relutância da maioria das entrevistadas em aceitar o problema:

(...) eu acho que não é tão grave, não consigo entender o porquê é tão grave, acho que não é tão grave. (R)

(...) eu não aceitava a doença e comecei a fazer tratamento com a psicóloga. (V)

A negação e a relutância inicial em buscar e/ou a aderir ao tratamento é bastante comum em casos de TA: "O medo acentuado de engordar, agravado pelo transtorno da imagem corporal, que diminui o insight sobre a doença, é um dos fatores que pode acentuar a resistência" (Duchesne \& Freitas, 2011, p. 391). Em especial, no tocante à bulimia nervosa, a negação pode ocorrer devido à conotação pejorativa associada ao problema. Em muitos casos, há o constrangimento em admitir o transtorno, a vergonha do problema e a tentativa de escondê-lo, uma vez que o comportamento bulímico é condenado socialmente (Dalgalarrondo, 2008). Isto remete à importância de conscientizar os familiares quanto ao problema, além de envolvê-los como integrantes dos programas terapêuticos.

(...) a família tem importante papel não apenas no tratamento dos filhos pequenos, dado que um dos primeiros sintomas do transtorno alimentar é a perda da noção que a pessoa tem da sua imagem corporal e a tendência, portanto, de negar a doença e achar que nada de mal possa the acontecer. (Silva, 2005, p. 117)

Para alguns especialistas, inclusive, as estimativas de incidência do problema na população podem não refletir a realidade; isto porque as baixas prevalências encontradas em pesquisas podem ser decorrentes do fato de que muitos indivíduos com TA se recusam a participar de estudos dessa natureza (Barlow \& Durand, 2008). Assim, o envolvimento de familiares e o fornecimento de informações e orientações sobre a natureza do transtorno são essenciais, no sentido de melhorar o prognóstico do tratamento:

Muitas vezes o TA não é visto nem compreendido com 
a seriedade que merece, o que dificulta e retarda a busca por ajuda médica, psicológica e nutricional, fundamentais nos casos desse transtorno. A falta de conhecimento e de aceitação desse transtorno como doença prejudica ainda mais o indivíduo acometido podendo, até mesmo, levá-lo à morte. (Nunes \& Vasconcelos, 2010, p. 540)

\section{Considerações Finais}

Este trabalho tem como meta central chamar atenção para questões relacionadas ao transtorno alimentar e à importância de seu tratamento. Os principais eventos percebidos pelas entrevistadas como associados ao aparecimento do problema foram conflitos nos relacionamentos interpessoais e pressões e/ou gozações/ pressão, por parte de terceiros, para o emagrecimento. Foi possível também observar, com a fala de cada paciente, a relação que elas têm com seu corpo e o quanto isso interfere no seu cotidiano. Todos esses conflitos podem precipitar o aparecimento do transtorno alimentar. Assim, seria interessante, por exemplo, o desenvolvimento e a implantação de programas de intervenção junto às escolas, no início da adolescência. Sugere-se que programas preventivos destinados à melhoria do funcionamento interpessoal dos adolescentes (no sentido de lidar com conflitos típicos da fase) e ao desenvolvimento de habilidades relacionadas ao autocontrole em situações que envolvem risco à construção de sua autoestima poderiam contribuir para evitar o aparecimento do transtorno alimentar, além de outros transtornos psicológicos em geral. O conjunto dos resultados deste estudo sugere que são diversas as formas pelas quais cada paciente lida com o transtorno alimentar. É de extrema importância atentar para o problema com seriedade, para que se possa realizar o tratamento de maneira mais eficaz. É importante ressaltar também que o trabalho em equipe é essencial na intervenção terapêutica com as pacientes, pois:

(...) a atuação de uma equipe interdisciplinar tornase fundamental, na medida em que participa, analisa e integra conhecimentos específicos de diversas áreas com o objetivo comum de promover e manter a saúde, a troca de conhecimentos facilita a atuação de cada elemento do grupo e através de uma linguagem comum às áreas envolvidas, é estabelecido um intercâmbio profissional nas interfaces do saber, ou seja, na interseção dos conhecimentos de uma e outra (ou outras) área. Cada ator desempenha suas funções específicas dentro de um planejamento conjunto da equipe, com coresponsabilidade no processo de decisão. (Shinkai \& Del Bel Cury, 2000, p. 1100)
O trabalho integrado, envolvendo também profissionais de áreas diversas, como Terapia Ocupacional (TO), Assistência Social, entre outros, pode contribuir, em conjunto com a psicologia e/ou áreas afins, para o desenvolvimento da consciência corporal dos pacientes com TA. Uma das metas seria minimizar as distorções perceptivas, para a construção de novas maneiras de olhar o corpo e a imagem corporal, de modo a promover melhorias na qualidade da interação do paciente com o outro e com as situações vivenciadas no cotidiano.

Frente aos prejuízos psicossociais causados, provavelmente pelo impacto do TA na vida cotidiana, o profissional (Terapeuta Ocupacional) pode ajudar os pacientes na construção de espaços mais saudáveis, em que o fazer cria possibilidades de resgate dos papéis ocupacionais, independência e autonomia, em busca de novas paixões, além do alimento. (Quiles-Cestari \& Ribeiro, 2012, p.7)

A atuação de terapeutas ocupacionais nas intervenções para TA ainda é bastante escassa atualmente. Muitas vezes, terapeuta ocupacional não é incluído nas equipes multiprofissionais. Talvez isto se deva à relativa escassez de informações disponíveis, até o presente momento, sobre a importância da atuação deste profissional nas equipes que realizam o tratamento de tal transtorno psiquiátrico. A TO pode contribuir na funcionalidade das pessoas com TA, auxiliando em aspectos diversos: na conscientização dos prejuízos das funções mentais, como memória, consciência e linguagem; no desempenho/habilidades requeridas para a execução das atividades; além disso, pode contribuir para a identificação das barreiras e facilidades que o paciente enfrenta na relação com seu entorno, que englobando fatores como o ambiente físico e social em que vivem e atitudes da pessoa (OMS, 2003). O trabalho do TO tem como objetivo, entre outros, auxiliar no desempenho ocupacional das pessoas que, por motivos físicos, mentais ou sociais, apresentam dificuldade na realização das atividades que sustentam a vida ocupacional (Quiles-Cestari \& Ribeiro, 2012). Indivíduos com TA podem, em função de perdas na funcionalidade, apresentar dificuldade em definir uma identidade própria e em reconhecer emoções; podem ainda tender ao isolamento e apresentar dificuldade em manter relacionamentos sociais com sentido e significado, além de possível empobrecimento da comunicação interpessoal e falta de empatia (Quiles-Cestari \& Ribeiro, 2012). A Terapia Ocupacional é uma área do conhecimento que pode contribuir com a reestruturação da rotina e a retomada dos papéis sociais, projetando, junto com a pessoa, um planejamento de vida presente e futuro, que contemple as suas limitações, potencialidades e desejos. Fazem-se 
necessárias pesquisas que correlacionem a quebra de rotina e perdas de papéis sociais com a manutenção e piora do diagnóstico.

\section{Referências}

Almeida, G. A. N., Santos, J. E. S., Pasian, S. R., \& Loureiro, S. R. (2005). Percepção de tamanho e forma corporal de mulheres: Estudo exploratório. Psicologia em Estudo, Maringá, 10(1), 27-35.

Alves, D., Pinto, M., Alves, S., Mota, A., \& Leirós, V. (2009). Cultura e imagem corporal. Motricidade, 5(1), $1-20$.

American Psychological Association [APA]. (2002). Manual diagnóstico e estatístico das doenças mentais. Texto Revisado. DSM-IV-TR. Porto Alegre: Artmed.

Barlow, D. H., \& Durand, V. M. (2008). Psicopatologia: Uma abordagem integrada. São Paulo: Cengage Learning.

Canzonieri, A. M. (2010). Metodologia da pesquisa qualitativa na saúde. Petrópolis: Vozes.

Damasceno, V. O., Vianna, V. R. A., Vianna, J. M., Lacio, M., Lima, J. R. P., \& Novaes, J. S. (2006). Imagem corporal e corpo ideal. Revista Brasileira Ciência e Movimento, 14(1), 87-96.

Dalgalarrondo, P. (2008). Psicopatologia e semiologia dos transtornos mentais ( $2^{\mathrm{a}} \mathrm{ed}$.). Porto Alegre: Artmed.

Duchesne, M., \& Freitas, S. (2011). Transtornos alimentares. In B. Rangé (Org.), Psicoterapias cognitivocomportamentais: Um diálogo com a psiquiatria $\left(2^{\mathrm{a}}\right.$ ed,, pp. 393-408). Porto Alegre: Artmed.

Ferriani, M. G. C., Dias, T. S., Silva, K. Z., \& Martins, C. S (2005). Autoimagem corporal de adolescentes atendidos em um programa multidisciplinar. Revista Brasileira Saúde Materno Infantil, Recife, 5(1), 27-33.

Gonzaléz N. P., Adierna, J. M., Aróstegui, I., \& Horcajo, M. J. (2001). Calidad de vida de los pacientes afectados de transtornos de alimentación. Gaceta Sanitária, 15(1), 18-24.

Goldenberg, M. (2005). Gênero e corpo na cultura brasileira. Psicologia Clínica, 17(2), 65-80.

Jacobi, C., Hayward, C., Zwaan, M., Kraemer, H., \& Agras, W. S. (2004). Coming to terms with risk factors for eating disorders: Application of risk terminology and suggestions for a general taxonomy. Psychological Bulletin, 130(1), 19-65.
Lee, S. L., Chan, Y. Y. L., \& Hsu, L. K. G. (2003). The intermediate: Term outcome of chinese patients with anorexia nervosa in Hong Kong. American Journal of Psychiatry, 160(5), 967-72.

Manzini, E. J. (2004). Entrevista semi-estruturada: Análise de objetivos e de roteiros. In Anais do Seminário Internacional sobre Pesquisa e Estudos Qualitativos (Vol. 1, pp. 1-10). Bauru: Universidade Sagrado Coração.

Menédez, T. B. (2007). Câncer de mama e imagem corporal: Uma busca através da dança do ventre. Trabalho de Conclusão de Curso, Fisioterapia. Universidade São Marcos, São Paulo. Recuperado de: http://br.monografias.com/trabalhos3/cancer-mamaimagem-corporal/cancer-mama-imagem-corporal. shtml

Minayo, M. C. D. S. (1993). O desafio do conhecimento cientifico: Pesquisa qualitativa em saúde (2a ed.). São Paulo/Rio de Janeiro: Hucitec-Abrasco.

Morais, L. V. (2006). A assistência do terapeuta ocupacional para pessoas com anorexia nervosa: Relato de experiência. Medicina, Ribeirão Preto [online], 39(3), 381-385. Recuperado de http://www.revistas.usp.br/ rmrp/article/view/394/395

Nunes, L. A., \& Vasconcelos, F. A. G. (2010). Transtornos alimentares na visão de meninas adolescentes de Florianópolis: Uma abordagem fenomenológica. Ciência \& Saúde Coletiva, 15(2), 539-550.

Oliveira, L. L., \& Hutz, C. S. (2010). Transtornos alimentares: O papel dos aspectos culturais no mundo contemporâneo. Psicologia em Estudo, Maringá, 15(3), 575-582.

Organização Mundial da Saúde [OMS]. (2009). Classificação estatística internacional de doenças e problemas relacionados à saúde CID-10 (Vol. 1, 10 ed. Rev.). São Paulo: Edusp.

Organização Mundial da Saúde [OMS]. (2003). Classificação Internacional de Funcionalidade - CIF. São Paulo: Edusp.

Peres, R. S., \& Santos, M.A. (2006). Contribuições do Desenho da Figura Humana para avaliação da imagem corporal na anorexia nervosa. Medicina, Ribeirão Preto, [online], 39(3), 361-370. Recuperado de http:// www.revistas.usp.br/rmrp/article/view/392/393.

Pinzon, V., \& Nogueira, F. C. (2004). Epidemiologia, curso e evolução dos transtornos alimentares. Archives of Clinical Psychiatry, 31(4), 158-160.

Quiles-Cestari, L. M., \& Ribeiro, R. P. P. (2012). Os papéis ocupacionais 
de mulheres com anorexia nervosa. Revista Latino-Americana de Enfermagem [online], 20(2), [08 telas]. Recuperado de: http://www. scielo.br/pdf/rlae/v20n2/pt_04.pdf

Saikali, C. J., Soubhia, C. S., Scalfaro, B. M., \& Cordás, T. A. (2004). Imagem corporal nos transtornos alimentares. Revista Psiquiátrica Clínica, 31(4), 164-166.

Santos, L. A. (2008). O corpo, o comer e a comida: Um estudo sobre as práticas corporais e alimentares no mundo contemporâneo. Salvador: Edufba.

Sibilia, P. (2004). O pavor da carne: Riscos da pureza e do sacrifício no corpo-imagem contemporâneo. Revista Famecos, 25(25), 68-84.

Silva, A. B. B. (2005). Mentes insaciáveis. Rio de Janeiro: Ediouro.

Shinkai, R. S. A., \& Del Bel Cury, A. A. (2000). O papel da odontologia na equipe interdisciplinar: Contribuindo para a atenção integral ao idoso. Caderno de Saúde Pública, Rio de Janeiro, 16(4), 1099-1109.

\section{Endereço para correspondência:}

Gabriela Andrea Leite Gonzalez

Endereço: Rua Conselheiro Moreira de Barros, 2892. São Paulo - SP

E-mail: gabriela.algonzalez@hotmail.com

\section{Endereço para correspondência:}

Ernindo Sacomani Junior Endereço: R. Aziz Atalhah, s/n Fragata 17519-000 Marilia, SP - Brasil.

\section{Endereço para correspondência:}

Regina de Cássia Rondina

Endereço: Universidade Estadual Paulista. Av. Hygino Muzzi Filho, 737. Marilia - SP.

E-mail: rcassiar@marilia.unesp.br 